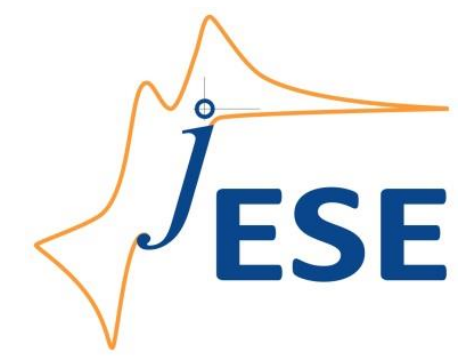

Open Access : : ISSN 1847-9286

www.jESE-online.org

Original scientific paper

\title{
Outstanding inhibitive effect of colchicine on aluminium alloy 6061 corrosion
}

\author{
Mudigere Krishnegowda Pavithra, Thimmappa Venkatarangaiah Venkatesha ${ }^{\bowtie}$, \\ Mudigere Krishnegowda Punith Kumar*, Nanjanagudu Subba Rao Anantha \\ Department of Chemistry, Kuvempu University, Shankaraghatta-577451, Shimoga, Karnataka, \\ India \\ *Department of Materials Engineering, Indian Institute of Science, Bangalore-560012, Karnataka, \\ India
}

${ }^{\square}$ Corresponding Author: drtvvenkatesha@yahoo.co.uk;Tel: +91-9448855079

Received: May 5, 2015; Revised: August 29, 2015; Accepted: September 14,2015

\begin{abstract}
The corrosion protection ability of colchicine (CC) on Aluminium alloy 6061 (AA6061) in $3.5 \% \mathrm{NaCl}$ medium was examined by potentiodynamic polarization, electrochemical impedance, and chronoamperometric techniques. About $99 \%$ of protection efficiency was achieved by $2 \mathrm{mM}$ concentration of $\mathrm{CC}$ in 3.5\% NaCl solution. The adsorption of CC on AA6061 surface obeys Langmuir isotherm by following both physisorption and chemisorption mechanism. Variation in the surface morphology of inhibited and uninhibited metal samples was examined by scanning electron microscopy.
\end{abstract}

\section{Keywords}

Corrosion inhibitor; Aluminium alloy; Potentiodynamic polarization; Electrochemical impedance spectroscopy, Adsorption isotherm

\section{Introduction}

Aluminium alloy 6061 (AA6061) has a remarkable technological importance and extensive applications in industries and machinaries due to low cost, light weight, high thermal and good corrosion resistance properties [1]. The corrosion resistance behaviour develops from the ability of metal to form a natural oxide film on its surface [2,3]. However, the localized corrosion takes place in an aggressive chloride medium and it leads to the breakdown of passive layer and resulted in pit formation [4,5]. Thus, chemical inhibitors are widely employed to minimize the corrosion of AA6061 in chloride media. Numerous organic compounds having $N, S$, and $O$ atoms along with $\pi$ 
electrons have been studied as proficient corrosion inhibitors for aluminium and its alloys in $3.5 \%$ $\mathrm{NaCl}$ solution [6-10]. But, now a day, the drug molecules find much attention in the field of corrosion inhibition. This is due to the strong chemical activity, low toxicity and negligible negative impact of drug molecules on the environment [11-13].

The drug molecules inhibits metallic corrosion by the process of adsorption and the magnitude of adsorption depends on nature of the metal, mode of adsorption, chemical structure of the inhibitor, and type of corrosion media [14]. As a result colchicine (CC) drug molecule which is an oral anti-inflammatory agent used for the treatment of gout, familial Mediterranean fever and pericarditis $[15,16]$ has been choosen based on its structural considerations. CC contains one nitrogen and six oxygen atoms along with large number of $\pi$-electrons in the six and seven membered ring system which may induce the adsorption behaviour of molecule on the metal surface. Meanwhile, according to literature study, there is no report found on the corrosion inhibition studies of $\mathrm{CC}$ in $3.5 \% \mathrm{NaCl}$ medium. Hence in the present investigation, the anticorrosive ability of CC on AA6061 in $3.5 \% \mathrm{NaCl}$ solution has been explored by electrochemical techniques and surface analysis.

\section{Experimental}

Preparation of Metal Samples.

The surface of AA6061 (Bhandari Metal House, K.R. Market, Bangalore, India)having composition $0.25 \% \mathrm{Cu}, 1.0 \% \mathrm{Mg}, 0.60 \% \mathrm{Si}, 0.20 \% \mathrm{Cr}$ and remainder being Al was polished with different grades of emery papers (grade No. 400, 600, 800, 1000, and 1200). Afterwards, the polished specimen was immersed in $10 \% \mathrm{NaOH}$ solution for $30 \mathrm{sec}$, degreased with acetone and rinsed by millipore water, dried and stored in desiccator. The AA6061 specimens of $1 \mathrm{~cm}^{2}$ area (exposed) with a $5 \mathrm{~cm}$ long stem isolated with araldite resin were used for electrochemical measurements.

\section{Preparation of solutions}

Corrosive medium was prepared from $\mathrm{AR}$ grade $\mathrm{NaCl}$ by using millipore water. The millipore water was obtained from Elix 3 Milli-pore system (Resistivity greater than $18 \mathrm{M} \Omega \mathrm{cm}$ at $25^{\circ} \mathrm{C}$ ). CC was obtained from Ramdev Chemicals India Pvt. Ltd., Mumbai and its structure is given in Figure 1. The different concentrations $(1.0,1.5,2.0 \mathrm{mM})$ of inhibitor solutions were prepared by dissolving specified amount of $\mathrm{CC}$ in $3.5 \% \mathrm{NaCl}$ solution. All the experiments were carried out in static condition and $3.5 \% \mathrm{NaCl}$ solution exhibit $\mathrm{pH} 6$ and the same $\mathrm{pH}$ has been maintained for each concentration of inhibitor solutions. Each experiment was carried out in triplicate, and the average values are reported.

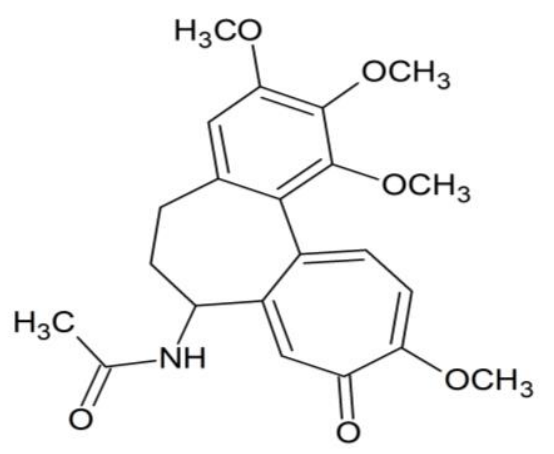

Figure 1. The structure of CC [16] 


\section{Electrochemical measurements}

The electrochemical measurements were conducted in a three electrode conventional glass cell using $\mathrm{CHI}$ 660C electrochemical analyzer ( $\mathrm{CH}$ instruments, Austin, USA). An AA6061 specimen (of $1 \mathrm{~cm}^{2}$ area), a platinum wire, and a $\mathrm{Ag} / \mathrm{AgCl}$ electrode were used as working, auxiliary, and reference electrodes for all the experiments. Prior to each potentiodynamic polarization and electrochemical impedance spectroscopic measurements (EIS), a stabilization period of $30 \mathrm{~min}$ was allowed to establish a steady state open circuit potential (OCP).

\section{Potentiodynamic polarization measurements}

The potentiodynamic polarization measurements were carried out over a potential range of $-200 \mathrm{mV}$ to $+200 \mathrm{mV}$ at OCP with a scan rate of $0.5 \mathrm{mV} \mathrm{s}{ }^{-1}$. The corrosion parameters such as corrosion potential $\left(E_{\text {corr }}\right)$, corrosion current density $\left(i_{\text {corr }}\right)$, and anodic $\left(\beta_{a}\right)$, and cathodic $\left(\beta_{c}\right)$ Tafel slopes were generated from the software installed in the instrument. The inhibition efficiency $\eta_{\mathrm{T}} / \%$ was evaluated from $i_{\text {corr }}$ values using the following expression:

$$
\eta_{\mathrm{T}} / \%=\frac{i_{\text {corr }}^{\mathrm{o}}-i_{\text {corr }}}{i_{\text {corr }}^{\circ}} \times 100
$$

where $i_{\text {corr }}^{\circ}$ and $i_{\text {corr }}$ are the corrosion current densities without and with CC, respectively.

\section{Electrochemical impedance measurements}

The impedance measurements were carried at OCP in the frequency range $1 \mathrm{mHz}$ to $100 \mathrm{kHz}$ with $5 \mathrm{mV}$ sine wave as the excitation signal. Impedance data were analyzed using ZSimp-Win 3.21 software. The percentage efficiency $\eta_{\mathrm{z}} / \%$ was evaluated from total resistance $\left(R_{\mathrm{t}}\right)$ values using the following equation

$$
\eta_{Z} / \%=\frac{R_{\mathrm{t}}-R_{\mathrm{t}}^{\circ}}{R_{\mathrm{t}}} \times 100
$$

Where $R_{\mathrm{t}}{ }^{\circ}$ and $R_{\mathrm{t}}$ are the total resistance (where $R_{\mathrm{t}}$ is the sum of $R_{1}$ and $R_{2}$ ) in the absence and presence of CC, respectively.

\section{Chronoamperometric measurements}

The chronoamperometric experiments were carried out by polarizing the working electrode anodically at $-0.68 \mathrm{~V}(\mathrm{Ag} / \mathrm{AgCl})$ for $600 \mathrm{~s}$ in $3.5 \% \mathrm{NaCl}$ solution.

\section{Surface morphological studies}

The surface morphology of AA6061 samples after immersion in corrosive medium in the absence and presence of inhibitor was analyzed using scanning electron microscope (JEOL, JSM 6400, JEOL Datum Shanghai Co. Ltd., Shanghai, PRC).

\section{Results and discussion}

\section{Potentiodynamic polarization (PDP) measurements}

The potentiodynamic polarization curves obtained for AA6061 in $3.5 \% \mathrm{NaCl}$ solution with or without CC are presented in Figure 2. It is evident from the figure that, both the cathodic and anodic curves are shifted towards lower current density in inhibited solution compared to $\mathrm{NaCl}$ 
solution. As a result it can be considered that both oxygen reduction and Al dissolution process are limited by CC and thus it acts as a mixed type inhibitor.

The corrosion kinetic data obtained from potentiodynamic polarization curves for AA6061 in $3.5 \% \mathrm{NaCl}$ having different concentrations of CC are tabulated in Table 1. It can be visualized from the table that by increasing the concentration of $\mathrm{CC}$ there exist a slight variation in both $\beta_{a}$ and $\beta_{\mathrm{c}}$ values and $E_{\text {corr }}$ values shifted towards more positive direction. This infers the formation of strongly adsorbed CC film on AA6061 surface.

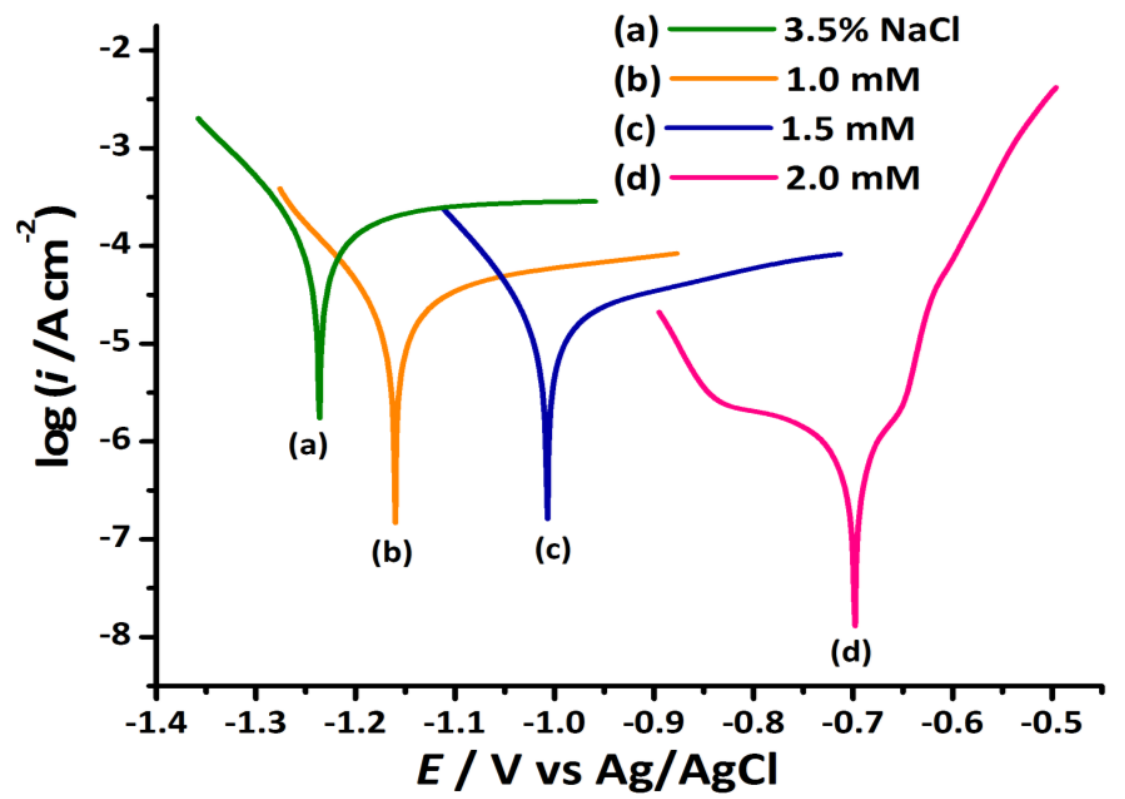

Figure 2. Potentiodynamic polarization curves obtained for AA6061 in $3.5 \% \mathrm{NaCl}$ in the absence and presence of $C C$.

Usually, in $3.5 \% \mathrm{NaCl}$ media, aluminium experience pitting corrosion because of the presence of destructive chloride ions. Hence, AA6061 dipped in $3.5 \% \mathrm{NaCl}$ shows high $i_{\text {corr }}$ value. But the $i_{\text {corr }}$ values get reduced in presence of CC. This specifies that in inhibited solution the CC molecules adsorb on the Al surface and decreases the aggressiveness of $\mathrm{Cl}^{-}$ions as well as protect the surface from being pitted. This suggests that CC inhibits the corrosion of AA6061 in $3.5 \% \mathrm{NaCl}$ solution and its efficiency increases with the increase of its content in the solution.

Table 1. Potentiodynamic polarization parameters obtained for AA6061 in $3.5 \% \mathrm{NaCl}$ in the absence and presence of $C C$

\begin{tabular}{cccccc}
\hline$C / \mathrm{mM}$ & $-E_{\text {corr }} / \mathrm{V}$ & $-\beta_{\mathrm{c}} / \mathrm{mV} \mathrm{dec}^{-1}$ & $\beta_{a} / \mathrm{mV} \mathrm{dec}^{-1}$ & $i_{\text {corr }} / \mu \mathrm{A} \mathrm{cm}$ & $\eta_{\mathrm{T}} / \%$ \\
\hline Blank & 1.236 & 10.063 & 2.308 & 162.5 & \\
1.0 & 1.160 & 11.516 & 2.876 & 25.08 & 85 \\
1.5 & 1.007 & 11.367 & 2.805 & 20.17 & 88 \\
2.0 & 0.698 & 21.923 & 2.417 & 0.6728 & 99 \\
\hline
\end{tabular}

On the other hand, it is apparent from the Figure 2 that a wide passive region can be witnessed in the anodic curve obtained for $2 \mathrm{mM} \mathrm{CC}$. This may be attributed to the formation of stable inhibitor film on the oxide layer which results in $99 \%$ protection efficiency. By reviewing these results, it can be concluded that CC behaves as a potential corrosion inhibitor for AA6061 by inhibiting the corrosion of aluminium by blocking the active sites of the metal surface. 


\section{Electrochemical impedance spectroscopy (EIS)}

EIS analysis was carried out to get information on the corrosion and inhibition mechanism of CC. The electrochemical impedance diagrams in the form of Nyquist and Bode plots obtained for AA6061 in $3.5 \% ~ N a C l$ in the absence and presence of CC are given in Figures 3 and 4, respectively. The EIS results were simulated by an electrical equivalent circuit shown in the inset of Figure 3 . In this circuit, $R_{\mathrm{S}}$ represents the solution resistance, $R_{1}$ is the charge transfer resistance corresponding to the corrosion reaction at the $\mathrm{Al} /$ solution interface, $R_{2}$ represents the polarization resistance, which reflects the protective property of the film, $C P E_{1}$ and $C P E_{2}$ represents the constant phase elements (CPE) as a substitute for the double-layer capacitance $\left(C_{\mathrm{dl}}\right)$. The impedance of CPE is defined as

$$
Z_{\mathrm{CPE}}=Q^{-1}(j \omega)^{-n}
$$

where $Q$ is the CPE constant, $\omega$ is the angular frequency, $j^{2}=-1$ is the imaginary number and $n$ is the CPE exponent which gives details about the degree of surface inhomogeneity resulting from surface roughness, inhibitor adsorption, porous layer formation etc.

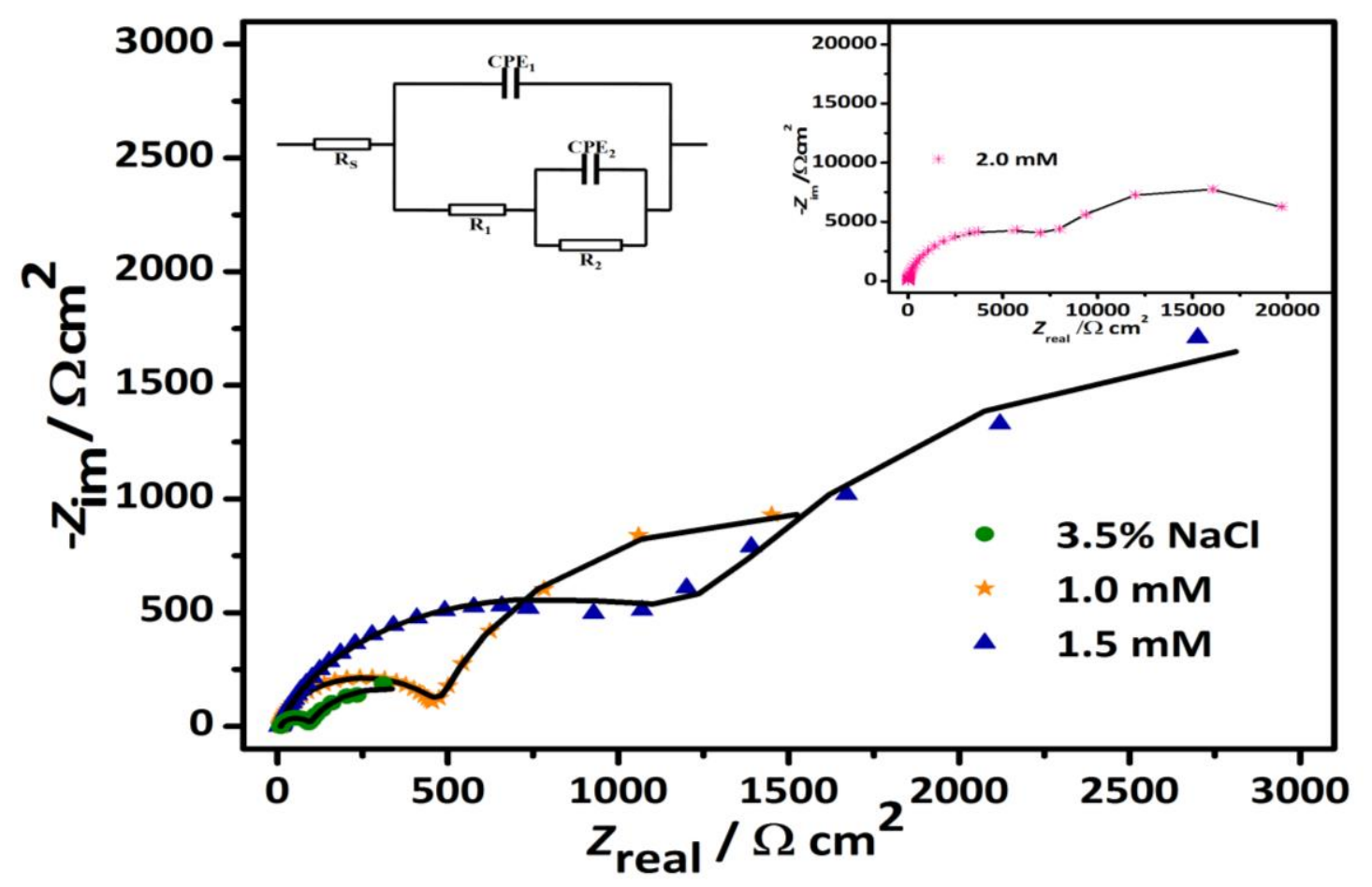

Figure 3. Nyquist plots for $\mathrm{AA6061}$ in $3.5 \% \mathrm{NaCl}$ in the absence and presence of different concentrations of CC.

Two capacitive loops were observed in Nyquist plots. The first capacitive loop at higher frequencies is related to the sum of charge transfer resistance and accumulation resistance (some free molecules or ions or corrosion products), while the second capacitive loop at lower frequencies corresponds to the film resistance. The diameter of these capacitive loops gets increased with increasing CC concentration and signifies the adsorption of inhibitor molecules on the metal surface. The adsorption of inhibitor molecules at the AA6061/ $\mathrm{NaCl}$ solution interface results in an increase of polarization resistance and reduces the corrosion rate of AA6061 [17]. 
Table 2. Electrochemical impedance parameters obtained for $\mathrm{AA6061}$ in $3.5 \% \mathrm{NaCl}$ in the absence and presence of different concentrations of CC

\begin{tabular}{ccccccccc}
\hline$C / \mathrm{mM}$ & $R_{s} / \Omega \mathrm{cm}^{2}$ & $Q_{1} / \mu \Omega^{-1} \mathrm{~S}^{\mathrm{n}} \mathrm{cm}^{-2}$ & $n_{1}$ & $R_{1} / \Omega \mathrm{cm}^{2}$ & $Q_{2} \mu \Omega^{-1} \mathrm{~S}^{\mathrm{n}} \mathrm{cm}^{-2}$ & $n_{2}$ & $R_{2} / \Omega \mathrm{cm}^{2}$ & $\eta_{z} / \%$ \\
\hline Blank & 10.12 & 171.8 & 0.865 & 87.12 & 12060 & 0.811 & 442.5 & \\
1.0 & 10.68 & 71.05 & 0.913 & 483.6 & 3562 & 0.912 & 2116 & 80 \\
1.5 & 6.934 & 155.2 & 0.827 & 1427 & 2322 & 0.920 & 3597 & 89 \\
2.0 & 6.891 & 24.47 & 0.936 & 9259 & 309.4 & 1.000 & 13620 & 98 \\
\hline
\end{tabular}

Data from Table 2 reveal that increasing the concentration of CC in chloride media leads to an increase in resistance value and decrease in CPE values. The decrease in $Q_{1}$ and $Q_{2}$ values may be due to the decrease in local dielectric constant and/or an increase in the electrical double layer thickness [18]. This infers $C C$ acts via adsorption at the $A A 6061 / \mathrm{NaCl}$ solution interface. Meanwhile the increase in $R_{1}$ and $R_{2}$ values point out that the amount of CC molecules adsorbed on the metal surface increases and the adsorbed inhibitor molecules forms a protective film on the electrode surface and consequently become a barrier to hinder the mass and charge transfer, resulting in an increase in the protection efficiency.

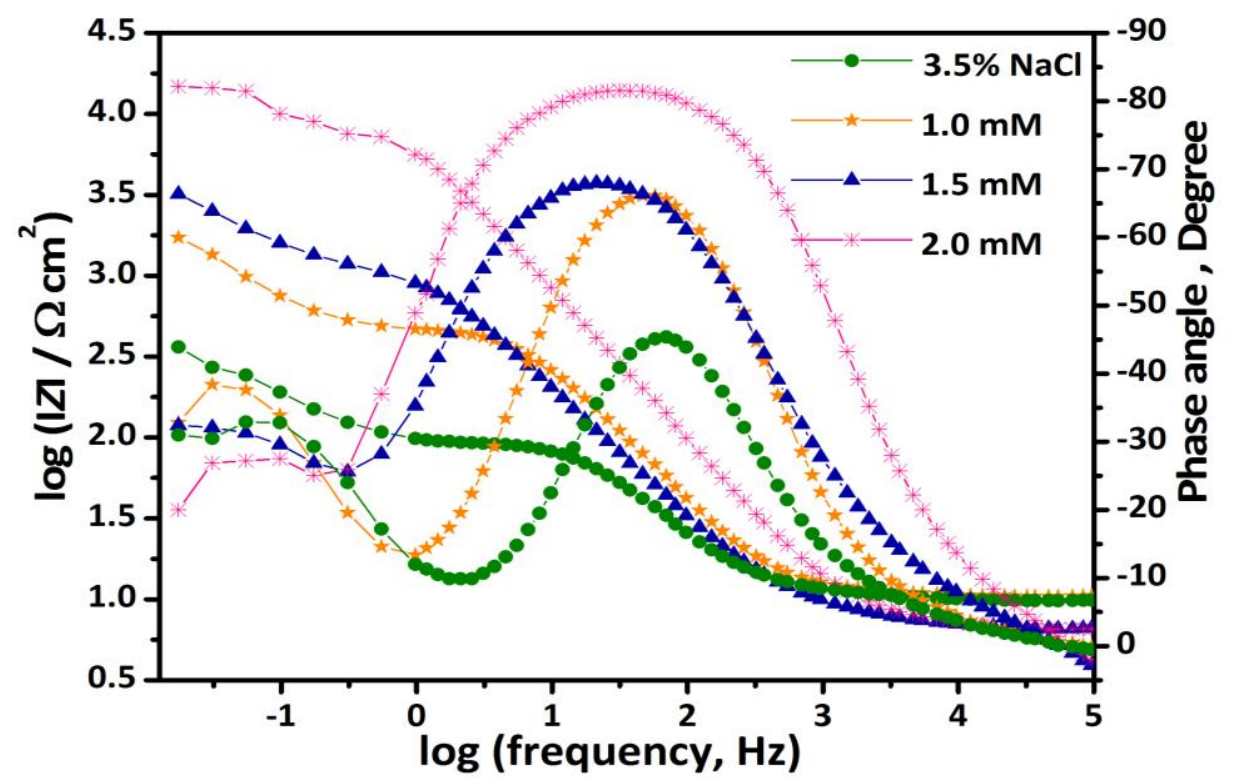

Figure 4. Bode plots for AA6061 in $3.5 \% \mathrm{NaCl}$ in the absence and presence of different concentrations of CC.

The Bode diagrams (Figure 4) that was plotted using the same experimental data in the Nyquist format. In the lower frequency range, impedance modulus ( $Z \mathrm{mod}$ ) gives information regarding the corrosion resistance behavior of metal samples. In Figure 4, Zmod values increases with increasing CC concentration compared to uninhibited solution and it reveals the better corrosion inhibition performance of $\mathrm{CC}$ in $\mathrm{NaCl}$ medium. Compared to uninhibited solution, the new phase shift is observed in the inhibited solutions. This means that the formation of inhibitor film changes the electrode interfacial structure and results in an extra time constant [19]. Hence two time constants can be evidenced in Figure 4 and this indicate that there are two major electrochemical kinetic processes on the electrode surface: the high frequency part is due to the adsorption of the CC molecule and the formation of the inhibitor film; the second time constant at medium frequency is due to the electrochemical corrosion process. Moreover, the inhibition effect is more remarkable 
and the middle frequency phase becomes loftier and wider at higher concentration [19] of CC ( $2 \mathrm{mM})$. These suggest the formation of compact, stable protective film of CC on AA6061 surface in $3.5 \% \mathrm{NaCl}$ solution.

\section{Chronoamperometric (CA) measurements}

The chronoamperometric experiments were performed so as to get information on the corrosion behaviour of AA6061 in $3.5 \% \mathrm{NaCl}$ solution in the absence and presence of CC at less negative potentials. The experiments were carried out by polarizing the working electrode anodically at $-680 \mathrm{mV}$ (vs. $\mathrm{Ag} / \mathrm{AgCl}$ ) for $600 \mathrm{~s}$ [20]. The current density values were obtained during the electrooxidation of $A A 6061$ in $3.5 \% \mathrm{NaCl}$ solution in the absence and presence of different concentrations of $\mathrm{CC}$ and the chronoamperometric curves are illustrated in Figure 5.

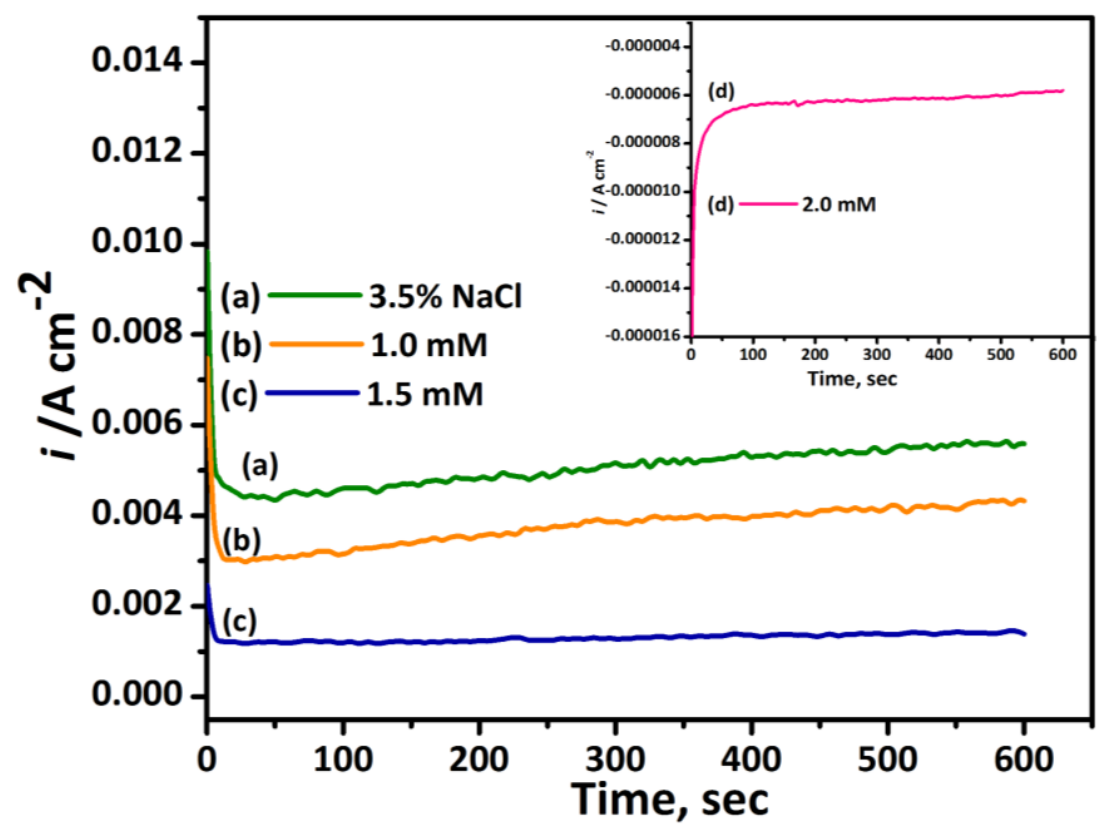

Figure 5. Chronoamperometric curves obtained for AA6061 in $3.5 \% \mathrm{NaCl}$ in the absence and presence of different concentrations of $C C$.

The absolute current of AA6061 in uninhibited solution is comparatively higher than inhibited solution. The addition of $\mathrm{CC}$ in to $\mathrm{NaCl}$ solution results in a reduction in the absolute current of AA6061 from the first moment till the end of the measurement. Besides, a significant decrease in the current was observed by increasing the concentration of CC. This supposes that CC improves the anticorrosive nature of $\mathrm{AA6061}$ in $3.5 \% \mathrm{NaCl}$ solution and hence it can be considered as a potential corrosion inhibitor.

\section{Adsorption isotherm}

The anticorrosive ability of metals can be improved by the adsorption of organic molecules and ions at the metallic surface. The molecular structure, electronic properties and distribution of charge in inhibitor molecules, the nature and surface charge of the metal, and the type of corrosive medium [21] have great influence on the process of adsorption of inhibitors on metal surface. In order to gain information on the adsorption behaviour of CC on AA6061 surface, the data obtained from the PDP and EIS techniques were tested with several adsorption isotherms. Many attempts were made to fit experimental data with adsorption isotherms like Langmuir, Flory-Huggins, Temkin, and Freundlich isotherms [22-24] (Equations 4-7). 
Langmuir adsorption isotherm:

$$
\frac{C}{\theta}=\frac{1}{K_{\text {ads }}}+C
$$

Flory - Huggins adsorption isotherm:

$$
\log \left(\frac{\theta}{C}\right)=\log K_{\mathrm{ads}}+a \log (1-\theta),
$$

Temkin adsorption isotherm:

$$
\theta=\frac{1}{f} \ln K_{\mathrm{ads}} C
$$

Freundlich adsorption isotherm:

$$
\log \theta=\log K_{\mathrm{ads}}+n \log C,
$$

where $C$ is the inhibitor concentration, $\theta$ is the degree of surface coverage defined as $\eta / 100$ and $K_{\text {ads }}$ is the adsorptive equilibrium constant, $f$ is the factor of energetic inhomogeneity, and the parameter $a$ is the number of water molecules replaced by inhibitor molecules on the metal surface.

The experimental data were fitted to Langmuir, Flory-Huggins, Temkin, and Freundlich isotherms and the corresponding curves are illustrated in Figure 6 . In the present investigation, the best fit was obtained with Langmuir adsorption isotherm and the plot of $C / \theta$ against $C$ clearly indicates that the linear regression coefficient $\left(R^{2}\right)$ and the slope values are very close to 1 . This reveals that the adsorption of CC on AA6061 obeys the Langmuir adsorption isotherm.
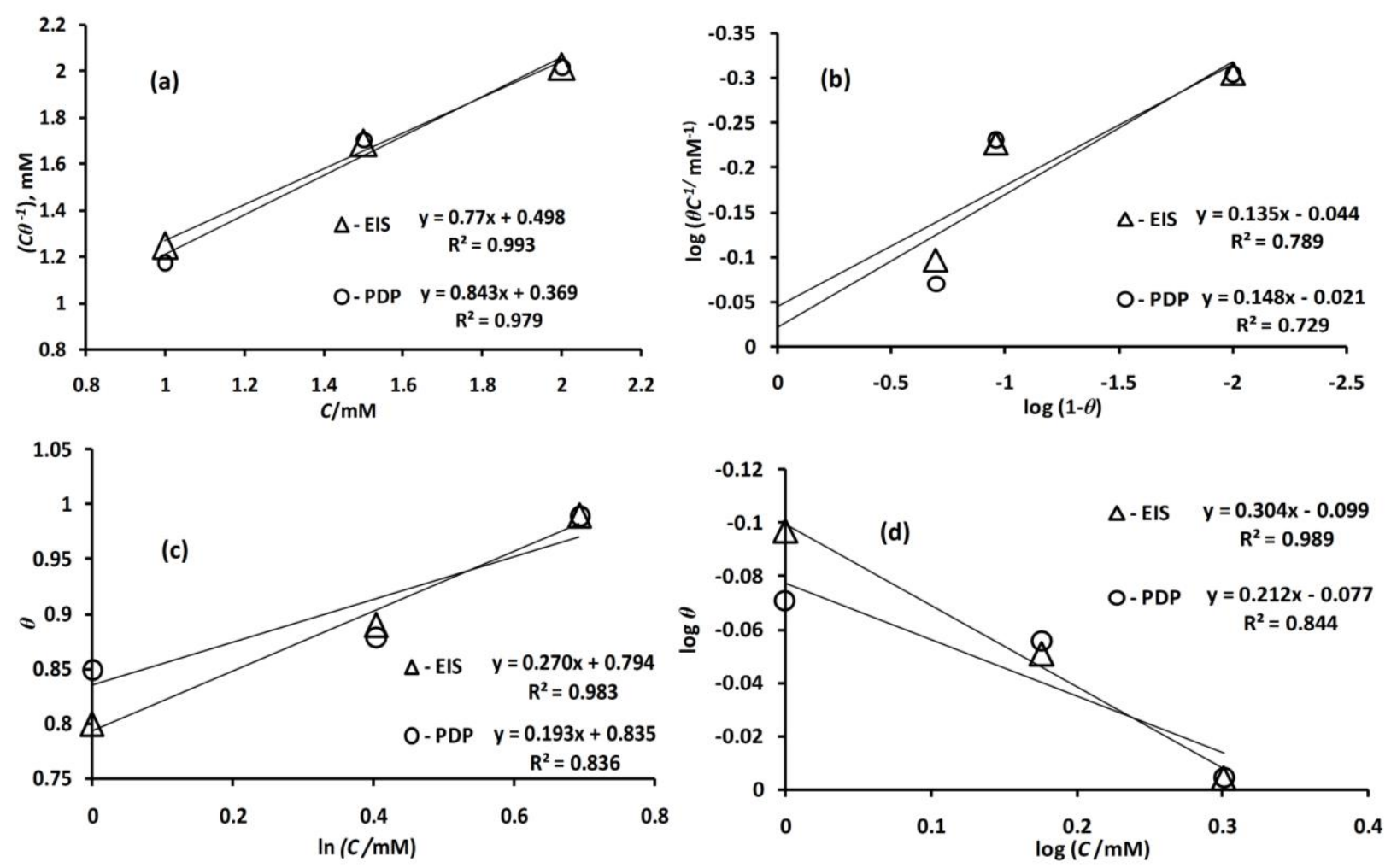

Figure 6. Adsorption isotherm plots obtained for the CC on the surface of AA6061 in $3.5 \% \mathrm{NaCl}$ (a) Langmuir, (b) Flory-Huggins, (c) Temkin and (d) Freundlich isotherms 
The equilibrium constant, $K_{\text {ads }}$ is related to the standard Gibbs free energy of adsorption $\Delta G^{\circ}$ ads by the relation:

$$
K_{\text {ads }}=\frac{1}{55.5} \exp \left(\frac{\Delta G_{\mathrm{ads}}^{\circ}}{R T}\right)
$$

where $R$ is the universal gas constant, $T$ is the thermodynamic temperature and 55.5 is the molar concentration of water in the solution.

Generally, the values of $\Delta G^{\circ}$ ads around $-20 \mathrm{~kJ} \mathrm{~mol}^{-1}$ or lower are consistent with physisorption and those around $-40 \mathrm{~kJ} \mathrm{~mol}^{-1}$ or higher involves chemisorption [25]. In the present work, the values of $\Delta G^{\circ}$ ads obtained for the adsorption of CC from PDP and EIS analysis are -29.93 and $-29.18 \mathrm{~kJ} \mathrm{~mol}^{-1}$, respectively. This ensures that the adsorption of CC on AA6061 involves both physisorption and chemisorptions. Meanwhile, the negative value of $\Delta G^{\circ}$ ads suggests the spontaneity of the adsorption of the CC molecules and the stability of the adsorbed layer on AA6061 surface.

\section{Surface morphological studies}

Figure 7 shows the surface morphology of AA6061 samples after immersion in $3.5 \% \mathrm{NaCl}$ in the absence and presence of $2 \mathrm{mM} \mathrm{CC}$. It can be clearly seen from the Figure 7a that AA6061 surface is strongly damaged with numerous pits in the absence of $\mathrm{CC}$ due to dissolution of metal in $\mathrm{NaCl}$ medium. But a smoother surface free from pits can be observed in the Figure $7 b$ due to the presence of CC which results in the formation of protective layer on AA6061. This signifies that CC hinders the dissolution of $\mathrm{Al}$ and thereby it reduces the pittig corrosion of $\mathrm{AA6061}$ in $3.5 \% \mathrm{NaCl}$.

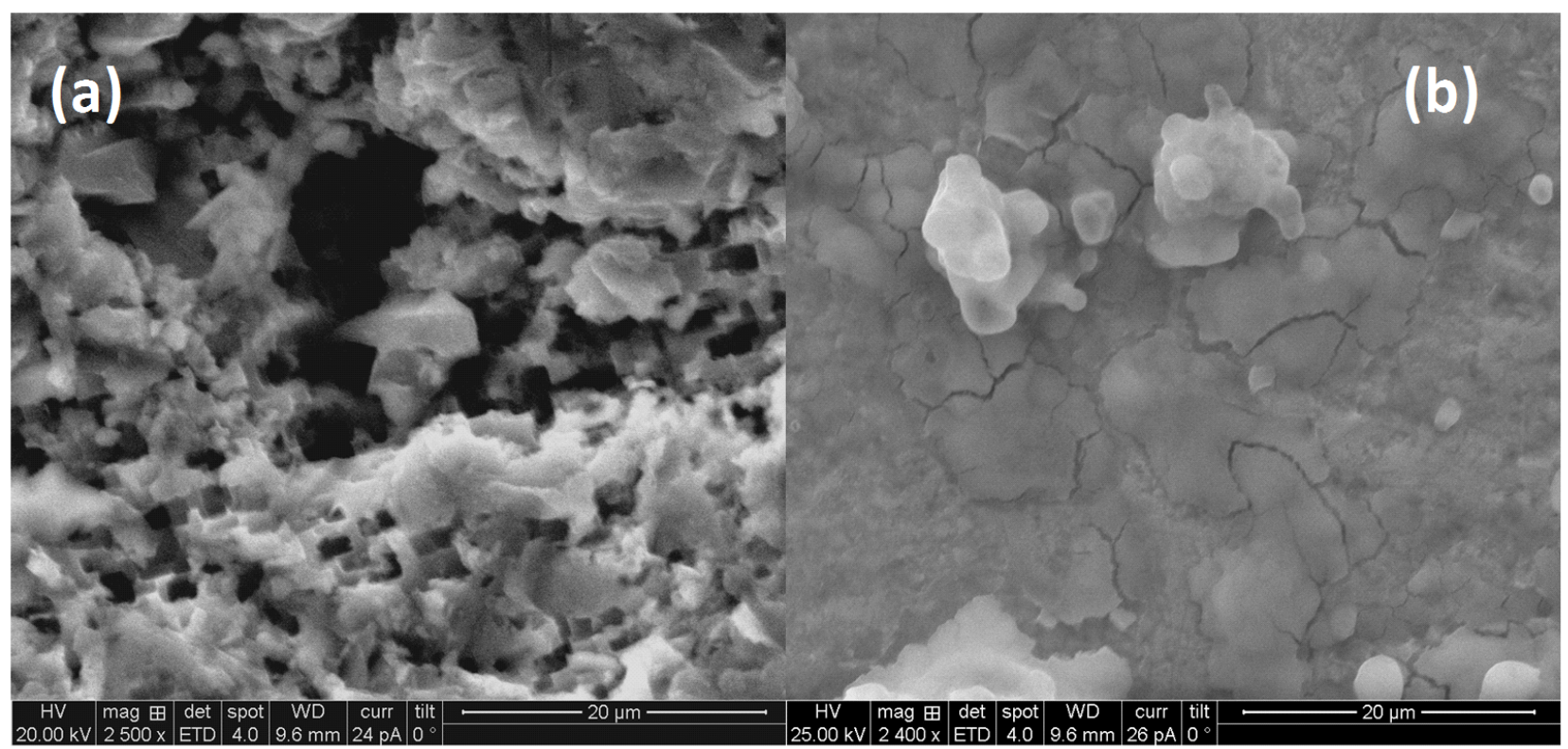

Figure 7. SEM micrographs of AA6061 immersed in (a) $3.5 \% \mathrm{NaCl}$ and b) $3.5 \% \mathrm{NaCl}+2.0 \mathrm{mMCC}$

\section{Mechanism of corrosion inhibition}

Aluminium has more electronegative potential value and hence, it undergoes oxidation very easily in an oxidizing media. This phenomenon leads to the formation of oxide layer $\left(\mathrm{Al}_{2} \mathrm{O}_{3}\right)$ on its surface by both cathodic and anodic reactions [26]. The mechanism of formation of oxide film on AA6061 surface is shown in Figure 8a. 


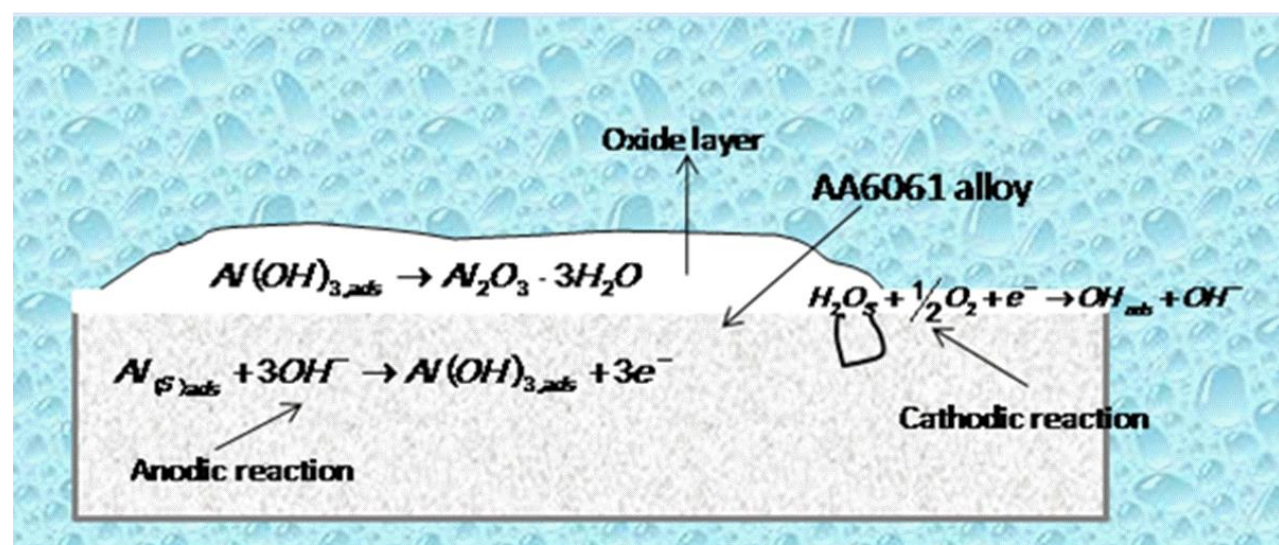

\section{(a) Mechanism of oxide layer formation}

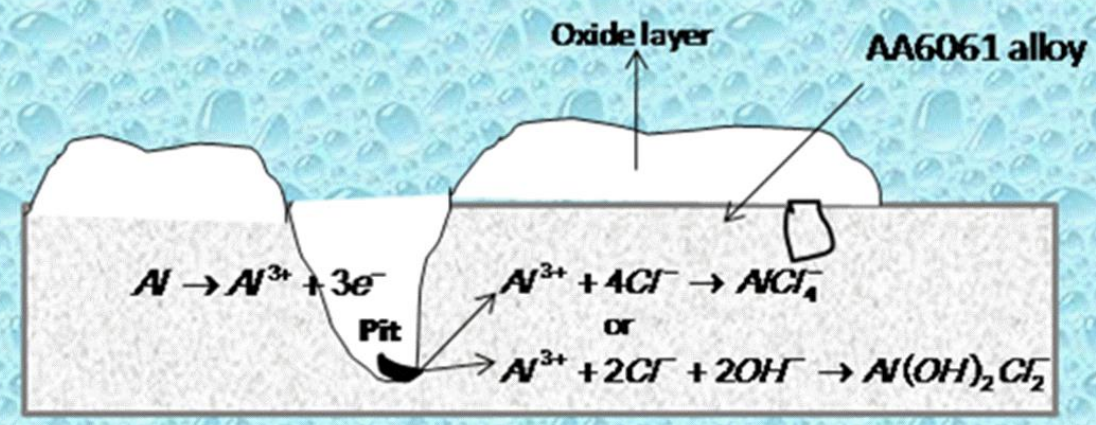

\section{(b) Mechanism of pitting corrosion}

$$
\mathrm{CC}_{(\mathrm{sod})}+\mathrm{xH}_{2} \mathrm{O}_{2 \mathrm{~s}} \rightarrow \mathrm{CC}_{(\mathrm{cos})}+\mathrm{H}_{2} \mathrm{O}
$$

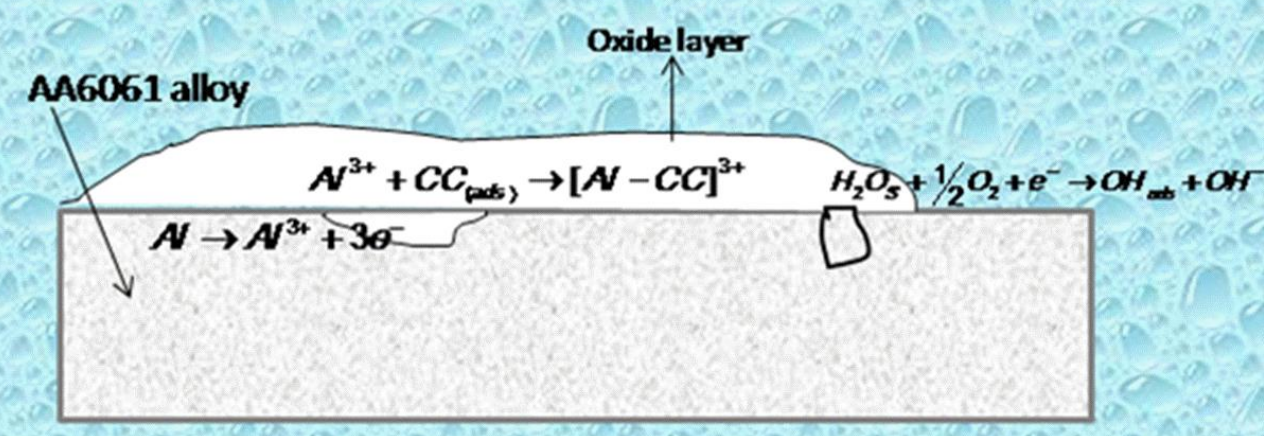

\section{(c) Mechanism of corrosion inhibition}

Figure 8. Mechanism of AA6061 corrosion and its inhibition by CC in $3.5 \% \mathrm{NaCl}$.

The presence of oxide layer on metal surface induces corrosion resistance property. However, in $3.5 \% \mathrm{NaCl}$ medium, aluminium undergoes pitting corrosion which results in the depletion of oxide layer. The mechanism of pitting corrosion is depicted in Figure $8 \mathrm{~b}$. In the presence of $3.5 \%$ $\mathrm{NaCl}$ media, the stability of the oxide layer decreases due to the presence of aggressive chloride ions [7]. The aggressive chloride ions penetrates through the oxide film and breakdown the aluminium oxide formed on the metal surface [27]. Then the adsorbed chloride ions reacts with $\mathrm{Al}^{3+}$ in the oxide lattice and results in the formation of oxychloride complexes, $\mathrm{Al}(\mathrm{OH})_{2} \mathrm{Cl}_{2}^{-}[28-31]$. The oxychloride complex reduces the stability of oxide film and intensifies the dissolution rate of aluminium [20]. 
On the other hand, all the experimental results reveal that the corrosion of AA6061 can be minimized in presence of CC. The electrochemical studies disclose that the inhibition performance of CC occurs through the process of electrostatic interaction. The mechanism of corrosion inhibition is given in Figure 8c. The inhibitor CC get adsorbed on metal surface by donor acceptor interactions between free electron pairs of four oxygen atoms present in the methoxy group and $\pi$ electrons of the phenyl ring and the vacant orbital of aluminium atom. According to the quantum chemical studies carried out by our research group, nitrogen and oxygen atoms, and $\pi$ - electrons in the phenyl ring and cycloheptatrienone ring, are the main active sites of adsorption of CC on metal surface [32]. As a result, CC gets adsorbed on AA6061 surface through these active sites and it prevents the formation of oxychloride complexes and inhibits metal dissolution reaction.

\section{Conclusions}

The pitting corrosion of $A A 6061$ can be minimized in the presence of $\mathrm{CC}$ in $3.5 \% \mathrm{NaCl}$ solution. CC acts as a proficient corrosion inhibitor through the process of adsorption. The PDP, EIS and CA studies disclose that CC forms a protective film on metal surface which results in an improvement in anticorrosive nature of AA6061 in $\mathrm{NaCl}$ medium. The adsorption of CC on AA6061 surface follows Langmuir adsorption isotherm via comprehensive adsorption mechanism. Variation in the surface morphology of metal samples also reveals the corrosion protection ability of CC.

Acknowledgement: The authors are grateful to the authorities of Department of Chemistry, Kuvempu University, Karnataka, India for providing lab facilities. Authors also thank Department of Science and Technology, New Delhi, Govt. of India [DST: Project Sanction No. 100/IFD/1924/20082009 dated 2.07.2008] for providing instrumental facilities.

\section{References}

[1] R. Banerjee, Ranjana, S.S. Panja, M.M. Nandi, Ind. J. Chem. Tech. 18 (2011) 309-313.

[2] S.S.A. Rehim, H.H. Hasan, M.A. Amin, Appl. Surf. Sci. 187 (2002) 279-290.

[3] A.A. El-Shafei, S.A. Abd El-Maksoud, A.S. Fouda, Corros. Sci. 46 (2004) 579-590.

[4] R. Ambat, E.S. Dwarakodasa, J. Appl. Electrochem. 24 (1994) 911-916.

[5] S. Sun, Q. Zheng, D. Li, J. Wen, Corros. Sci. 51 (2009) 719-727.

[6] A. Balbo, A. Frignani,V. Grassi, F. Zucchi, Corros. Sci. 73 (2013) 80-88.

[7] E-S. M. Sherif, Int. J. Electrochem. Sci. 7 (2012) 4847 - 4859.

[8] L. Song-mei, Z. Hong-rui, L. Jian-hua, Trans. Nonferrous Met. SOC.China 17 (2007) 318-325.

[9] A. Yurt, G. Bereket, C. Ogretir, J.Mol. Struct.: THEOCHEM 725 (2005) 215-221.

[10] S.V. Lamaka, M.L. Zheludkevich, K.A. Yasakau, M.F. Montemor, M.G.S. Ferreir, Electrochim.Acta 52 (2007) 7231-7247.

[11] I. Ahamad, R. Prasad, M. A. Quraishi, J. Solid State Electrochem. 14 (2010) 2095-2105.

[12] A. K. Singh, M. A. Quraishi, Corros. Sci. 52 (2010) 152-160.

[13] R. S. Abdel Hameed, E. A. Ismail, A. H. Abu- Nawwas. Hussin I. AL-Shafey Int. J. Electrochem.Sci. 10 (2015)2098-2109.

[14] G.Y. Elewady,I.A. El-Said ,A .S.Fo, Int. J. Electrochem. Sci. 3 (2008) 177-190.

[15] C. Giuseppe, C. David ,P. Stefano, Europ. J. Internal Med. 21 (2010) 503-508.

[16] Drug Bank directory, http://www.drugbank.ca/drugs/DB01394, May (2015).

[17] R. Solmaz , E. A. Sahin, A. Doner, G. Kardas, Corros. Sci. 53 (2011) 3231-3240.

[18] W. Che, H.Q. Luo, N.B. Li, Corros. Sci. 53 (2011) 3356-3365.

[19] H. Gao, Q. Li , F.N. Chen, Y. Dai, F. Luo, L.Q. Li, Corros. Sci. 53 (2011) 1401-1407.

[20] E-S. M. Sherif, Int. J. Electrochem. Sci.6 (2011) 1479-1492. 
[21] H. Gerengi, Ind. Eng. Chem. Res. 51 (2012) 12835-12843.

[22] M. K. Pavithra, T. V. Venkatesha, M. K. Punith Kumar, N. S. Anantha, Res. Chem.Intermed. 41 (2015) 5781-5796.

[23] K.K. Anupama, J. Abraham, Res. Chem.Intermed. 39 (2013) 4067-4080.

[24] A. Khadraoui, A. Khelifa, Res. Chem.Intermed. 39(2013) 3937-3948.

[25] S.M.A. Hosseini, M.J. Bahrami, A. Dorehgirae, Mater. Corros. 63 (2012) 7627-7635.

[26] E. M. Sherif, S.M. Park, Electrochim. Acta 51 (2006) 1313-1321.

[27] M. K. Pavithra, T. V. Venkatesha, M. K. Punith Kumar, N. S. Anantha, J.Electrochem. Sci. Eng. 5(2015) 115-127.

[28] T. H. Nguyen, R. T. Foley, J. Electrochem. Soc. 129 (1982) 27-32.

[29] Z. Szklarska-Smialowska, Corros. Sci. 41 (1999) 1743-1767.

[30] F. Hunkeler, G. S. Frankel, H. Bohni, Corrosion (NACE) 43 (1987) 189-191.

[31] N. Sato, Corros. Sci. 37(1995) 1947-1967.

[32] M. K. Pavithra, T. V. Venkatesha, M. K. Punith Kumar, N. S. Anantha, Res. Chem.Intermed. DOI 10.1007/s11164-015-2158-3, (2015) http://link.springer.com/article/10.1007/s11164$\underline{015-2158-3}$

(C) 2015 by the authors; licensee IAPC, Zagreb, Croatia. This article is an open-access article distributed under the terms and conditions of the Creative Commons Attribution license (http://creativecommons.org/licenses/by/4.0/) (cc) EY 